\title{
ESTRATÉGIA E TÁTICA: A BUSCA POR CONCEITOS ÚTEIS AO VOLEIBOL
}

\section{ARTIGO ORIGINAL}

GUIMARÃES, Michel ${ }^{1}$

GUIMARÃES, Michel. Estratégia e tática: A busca por conceitos úteis ao voleibol. Revista Científica Multidisciplinar Núcleo do Conhecimento. Ano 05, Ed. 08, Vol. 03, pp. 69-80. Agosto de 2020. ISSN: 2448-0959, Link de acesso: https://www. nucleodoconhecimento.com.br/educacao-fisica/estrategia-etatica

\section{RESUMO}

As palavras estratégia e tática são muito utilizadas no meio desportivo, inclusive na prática do voleibol. Muitos treinadores e atletas utilizam-se destas palavras sem entender o real significado de cada uma, e isso é devido, em grande parte, à falta de material didático que esclareça tais conceitos e faça uma ligação direta com a utilização no esporte, sendo esta questão problematizada pelo presente artigo. Este estudo tem como objetivo expor os conceitos de estratégia e tática com clareza sobre seus respectivos significados e sobre como aplicá-los, com convicção, principalmente, no meio esportivo do voleibol. Para isto, o artigo traz conceitos sobre estratégia e tática, bem como algumas utilizações dos termos nos âmbitos militar, corporativo e desportivo, por meio da pesquisa bibliográfica. Dentre as considerações que este artigo permite arrematar, destaca-se o esclarecimento sobre o conceito de tática individual no desporto, vem permitir, a qualquer estrategista, uma reflexão sobre a importância da atuação individual do jogador dentro da tática de equipe.

\footnotetext{
${ }^{1}$ Licenciado em Educação Física (UNIASSELVI), Especialista em Educação Física Escolar (UCEFF), Especialista em Treinamento Desportivo (UNOPAR).
} 
Palavras-chave: Estratégia, tática, voleibol.

\section{INTRODUÇÃO}

Os conceitos de estratégia e tática são muito bem definidos no cenário militar por serem utilizados, há muito tempo, em batalhas e guerras. De acordo Sun Tzu (2016), os relatos históricos falam da utilização destes conceitos desde aproximadamente dois mil e quinhentos anos atrás, na China antiga, tendo como seu maior precursor o próprio general chinês, Sun Tzu.

No cenário corporativo, faz algum tempo que as grandes empresas se utilizam dos conceitos trazidos por Sun Tzu, circunscritos com os devidos e necessários ajustes ao ambiente empresarial. As empresas e organizações os utilizam para planejar e estruturar seu crescimento no mercado, delineando que cada nível hierárquico da organização corporativa tenha sua parcela de contribuição.

No desporto, os termos 'estratégia' e 'tática' também são utilizados largamente, como registra-se em literaturas e mídias ligadas à área. No entanto, parecem não estar muito claros quanto aos seus significados e suas contribuições dentro do processo desportivo.

Contribuindo com o diagnóstico supracitado, Bompa (2005) fala sobre a confusão que ainda existe em relação aos conceitos de estratégia e tática no desporto, relatando sobre a preferência regional na utilização dos termos, informando que, em alguns lugares, prefere-se o uso da palavra estratégia e, em outros, o uso da palavra tática para definir as mesmas ações.

Este estudo trará a origem dos conceitos de estratégia e tática, bem como algumas outras versões utilizadas nos ambientes militar, corporativo e o desportivo.

Ao final, espera-se apresentar uma proposta conceitual acerca de estratégia e tática desportiva para o uso, principalmente, no meio desportivo do voleibol. 


\section{ESTRATÉGIA E TÁTICA: ORIGEM}

Segundo Meirelles (1995 apud SANTOS, 2011), a palavra estratégia tem origem grega e significava, em um primeiro momento, 'a arte do geral', mas com o passar do tempo e sua utilização nos campos de batalha, sofreu alterações, chegando a ser definida como "General, a arte e a ciência de conduzir um exército por um caminho".

De acordo com Bompa (2005) também a tática, assim como a estratégia, tem origem grega, onde tática era chamada de taktika e significava modos de organização, enquanto que, estratégia era chamada de strategos e significava geral ou arte do geral.

Ao buscar os significados de ambas as palavras no dicionário, encontra-se a seguinte definição para estratégia: "sf 1. Organização e planejamento das operações de guerra; estratagema, tática; 2. por ext ardil, manha, astúcia”. (AMORA, 2000, p. 292). Já tática é definida desta forma: "sf 1. Arte de dispor e ordenar tropas para o combate; 2. fig Maneira hábil que se emprega para dirigir qualquer negócio" (AMORA, 2000, p. 710).

Estratégia e tática, são, portanto, palavras de origem grega, aplicadas, antigamente, com maior ênfase na área militar.

\section{ESTRATÉGIA E TÁTICA NO ÂMBITO MILITAR}

As expressões 'estratégia' e 'tática' ganharam maior notoriedade após o registro e a publicação da obra 'A Arte da Guerra', texto milenar no qual se apresenta a forma como o General chinês Sun Tzu aplicava os dois conceitos nas batalhas e nas guerras que se envolvia.

De acordo com Herrera (2007), em sua obra, Sun Tzu comenta que as táticas responsáveis pelas vitórias em batalhas eram percebidas facilmente pelos homens. No entanto, as estratégias por ele arquitetadas, responsáveis por nortear as táticas, essas não eram notadas. 
O parágrafo anterior nos faz refletir sobre a importância da estratégia para se obter grandes vitórias e, ainda, nos faz acreditar que a estratégia precede a tática. Corroborando com a ideia anterior, temos o seguinte:

Estratégia e tática são classificadas separadamente na teoria da guerra, porque os dois termos têm dimensões únicas. A estratégia se aplica a amplos espaços, períodos longos e grandes movimentos de tropas. A tática se refere a espaço, tempo e contingente menores. A estratégia precede o plano de guerra, enquanto as táticas são a própria ação no campo de batalha. (BOMPA, 2005, p. 38-39).

Diante do exposto acima, é possível inferir que nos tempos citados havia uma certa hierarquia na utilização das expressões, uma ordem na qual se percebe uma cronologia, onde se propõe a definição, primeiramente, de uma estratégia para se vencer a guerra, para depois definir-se quais serão as táticas utilizadas em cada batalha.

A hierarquização dos conceitos supracitados é também mencionada por Chiavenato (2004), onde encontra-se exposta a ideia de que a aplicação de uma ou mais estratégias constitui o caminho para se vencer uma guerra. Assim sendo, para cada estratégia pode ser necessária uma série de ações táticas. $O$ autor cita também a mobilização de uma tropa específica como uma dessas ações táticas.

Sobre o processo decisório em uma guerra, ao avaliar os fatores que levam o general a decidir sobre quais estratégias e táticas usar, Sun Tzu revela: "quem conhece a si mesmo e conhece o inimigo, pode garantir a vitória; quem conhece o tempo e o terreno, a alcançará de modo absoluto" (TZU, 2011, p. 82).

Desta forma, evidencia-se que o plano estratégico leva aos planos táticos, e que ambos são definidos levando-se em consideração: as características da própria tropa, as características da tropa inimiga, as características das estações do ano em que as batalhas são travadas, e ainda, os locais onde as batalhas acontecem. 


\section{ESTRATÉGIA E TÁTICA NO ÂMBITO CORPORATIVO}

Ato contínuo, em termos empresariais, "a estratégia é a mobilização de todos os recursos da empresa no âmbito global visando atingir os objetivos a longo prazo" (CHIAVENATO, 2004, p. 192). O autor define que a tática é um plano menor, com utilização específica de recursos, visando o cumprimento de parte da estratégia geral.

Exemplificando a interação entre as duas concepções, e ainda em uma perspectiva temporal, Chiavenato diz: "o planejamento para cinco anos na empresa requer uma estratégia, a qual se ligam os planos táticos de cada ano compreendido neste período" (CHIAVENATO, 2004, p. 192).

Konichi Omae (apud HERRERA, 2006) apresenta a ideia de que a estratégia corresponde às ações direcionadas a aumentar a força da organização frente aos seus concorrentes. Ainda Herrera (2007) cita o dicionário Houaiss ao expor uma de suas conceituações sobre tática, definindo-a como a forma hábil de superar disputas e adversidades através de arranjo e organização.

No mundo corporativo, segundo Chiavenato (2004), as estratégias são definidas através do planejamento estratégico da empresa, dentro de uma trajetória que perpassa as classes mais altas da organização, como a presidência e as diretorias, enquanto que as táticas são definidas através do planejamento tático, perpassando a classe intermediária da organização, como as gerências.

Todo o processo que fundamenta a formulação dos planejamentos supracitados, o estratégico e o tático, leva em consideração análises sobre o ambiente interno e externo da empresa, onde são elencados os pontos fortes e os fracos da organização, paralelamente com as oportunidades e as ameaças do mercado em que atua.

Portanto, neste universo, o corporativo, avaliar bem a sua própria condição de funcionamento e produtividade, e ainda ter uma real clareza sobre como está a demanda do mercado e a atuação de seus concorrentes, são os passos fundamentais para que se conquiste o sucesso. 


\section{ESTRATÉGIA E TÁTICA NO ÂMBITO DESPORTIVO COLETIVO}

De outro vértice, no âmbito desportivo coletivo, inicialmente, insta trazer à baila que Bompa (2005, p. 5) considera que "os desportos coletivos estão entre os mais dinâmicos, excitantes, espetaculares e complexos desportos, cativando a maioria dos adolescentes que sonham em se tornar o próximo herói de milhões de fãs".

Ao buscar-se a definição de desporto no dicionário, encontra-se a relação deste com a palavra esporte, a qual pode ser assim definida: "sm 1. Prática de exercícios físicos ou jogos, individualmente ou em equipes; desporte; 2. Divertimento, distração; 3. Adj 2 gên diz-se da roupa confortável, não formal” (AMORA, 2000, p. 285).

De acordo com a definição anterior, um desporto é também um jogo que, por sua vez, segundo Cavallari (2013, apud BORIM, [201-]), é caracterizado por conter pelo menos dois componentes, sendo eles o regramento e a característica competitiva. Ou seja, para que seja caracterizada como um jogo de fato, a atividade deve ser organizada pelo cumprimento de uma regra e pela busca de um vencedor.

Muito utilizados no meio desportivo, os termos estratégia e tática são conceitos que se entrelaçam com facilidade. No entanto, como vimos em outros âmbitos, não são a mesma coisa e, embora busquem um mesmo fim, que é o de superação de uma situação ou de um opositor, devemos saber distingui-los e apontar o papel de cada um.

A estratégia reflete a intenção do estrategista que, como é esperado em um ambiente competitivo, não se revela aos olhos dos oponentes. Ela tem ligação com o que se pretende alcançar e ao porquê se deve alcançar, enquanto que a tática nos remete a como alcançar. Por exemplo, a estratégia de uma equipe qualquer, de uma modalidade qualquer, pode ser de focar seu jogo no contra-ataque devido à superioridade técnica do adversário. A partir daí, surge a necessidade da elaboração de um plano tático, indicando como a equipe se posicionará para defender, como deverá recuperar a posse da bola, e tão logo a tenha conquistado, como executará o 
contra-ataque. Portanto, a estratégia reflete a intenção, enquanto a tática revela a forma de implementa-la.

Utilizando-se do exemplo mencionado no parágrafo anterior, percebe-se que a suposta equipe decidirá por uma estratégia específica após a comparação entre as suas próprias forças e as forças do adversário, o que revela a importância de se conhecer as próprias características e também as características do seu oponente ante à elaboração de planos estratégicos e táticos vencedores. A necessidade de se conhecer o adversário está contida na definição de Baacke (apud CONFEDERAÇÃO BRASILEIRA DE VOLEIBOL, 1998, p. 161), sobre tática, onde ele diz: "tática é a totalidade de ações individuais e coletivas, de ataque e de defesa que, baseada nas regras e na maneira de jogar do adversário, determinam a concepção da estrutura do jogo para obtenção do melhor resultado".

Como se vê no conceito definido por Baacke (apud CONFEDERAÇÃO BRASILEIRA DE VOLEIBOL, 1998, p. 161), é notável a relevância do desportista ter conhecimento sobre as regras da modalidade em que atua, justaposto ao conhecimento sobre o adversário, para a elaboração dos planos de jogo, tanto ofensivos quanto defensivos.

As modalidades esportivas em que os adversários se enfrentam diretamente são praticadas através de ações de ataque e de defesa, as quais, para que ocorram com coerência, devem seguir estratégias e táticas ofensivas e defensivas previamente definidas. Sobre isso, Bompa (2005, p. 39) afirma que "equipes e jogadores realizam ações de ataque ou defesa em um jogo, de acordo com planos táticos preestabelecidos. Tais ações táticas devem fazer parte da estrutura estratégica do jogo".

Quando analisamos modalidades esportivas coletivas, precisamos dividir a tática em tática coletiva e tática individual, isto para que a análise seja mais completa, pois, vejamos: se uma estratégia orienta táticas, quando essas táticas orientam as ações de mais de um jogador, é de se esperar que tais ações não sejam uniformes entre todos os jogadores, por mais que sejam da mesma equipe e por mais que as situações sejam semelhantes. Cada jogador tem uma forma própria de interpretar, decidir e agir 
frente a uma situação específica, e ainda que determinada situação se apresente igualmente a jogadores submetidos à mesma tática coletiva, a resposta destes jogadores será potencialmente diferente. A essa capacidade singular de cada jogador dá-se o nome de tática individual.

Sobre a tática individual, a Confederação Brasileira de Voleibol (CBV), através de uma de suas apostilas, traz o seguinte conceito: "tática individual é a capacidade que o atleta tem de dentro de um tempo disponível, analisar, decidir e responder a uma situação de jogo visando a obtenção do melhor resultado" (CONFEDERAÇÃO BRASILEIRA DE VOLEIBOL, 1998, p. 94).

Segundo Lerbach et al (2002, p. 24), "a tática individual é a utilização perceptiva da técnica no cálculo das reações do adversário".

Seguindo o raciocínio de que a lide dos esportes coletivos permite e provoca a ordenação da tática em coletiva e individual, e contando com a contribuição do que leciona Carvalho (2014) sobre estratégia e tática corporativa, cabe apontar algumas características que diferenciam a estratégia, a tática coletiva e a tática individual, entre si, de maneira a entendê-las melhor, como traz o quadro a seguir:

Quadro 1 - Características de estratégia, tática coletiva e tática individual.

\begin{tabular}{|c|c|c|}
\hline ESTRATÉGIA & TÁTICA COLETIVA & TÁTICA INDIVIDUAL \\
\hline $\begin{array}{l}\text { É uma ferramenta de } \\
\text { PLANEJAMENTO. }\end{array}$ & $\begin{array}{l}\text { É uma ferramenta de } \\
\text { EXECUÇÃO. }\end{array}$ & $\begin{array}{l}\text { É uma ferramenta } \\
\text { exclusivamente } \\
\text { INDIVIDUAL. }\end{array}$ \\
\hline $\begin{array}{ll}\text { Visa } & \text { um } \\
\text { OBJETIVO. } & \end{array}$ & Visa uma META. & $\begin{array}{l}\text { Visa SUPERAR uma } \\
\text { SITUAÇÃO. }\end{array}$ \\
\hline $\begin{array}{lll}\text { Está associada ao } & \text { ao } \\
\text { QUE FAZER e ao } \\
\text { PORQUE FAZER. }\end{array}$ & $\begin{array}{l}\text { Está associada } \\
\text { COMO FAZER. }\end{array}$ & $\begin{array}{l}\text { Junção } \\
\text { QUE FAZER } \\
\text { COMO FAZER. }\end{array}$ \\
\hline
\end{tabular}




\begin{tabular}{|l|l|l|l|}
$\begin{array}{l}\text { Trata do futuro, é } \\
\text { PROATIVA. }\end{array}$ & $\begin{array}{l}\text { Trata do presente, pode } \\
\text { ser ATIVA ou REATIVA. }\end{array}$ & $\begin{array}{l}\text { Trata do presente } \\
\text { imediato, é SUPER } \\
\text { REATIVA. }\end{array}$ \\
\hline $\begin{array}{l}\text { Atuação abrangente, é } \\
\text { um PLANO MAIOR. }\end{array}$ & $\begin{array}{l}\text { Atuação reduzida, é um } \\
\text { PLANO MENOR. }\end{array}$ & $\begin{array}{l}\text { Atuação restrita, é um } \\
\text { PLANO ESPECÍFICO. }\end{array}$ \\
\hline $\begin{array}{l}\text { Contém } \\
\text { TÁTICAS. }\end{array}$ & Faz parte da & Faz parte das \\
& ESTRATÉGIA e contém & TÁTICAS COLETIVAS. \\
TÁTICAS INDIVIDUAIS. &
\end{tabular}

Fonte: elaboração do autor.

Tem-se, portanto, que para as modalidades esportivas coletivas é possível conceituar que a estratégia serve como guia para a aplicação de táticas; a tática coletiva orienta a forma como a equipe se portará diante das situações ofensivas e defensivas; e a tática individual se caracteriza pelas decisões que cada jogador tomará na sua hora de agir.

\section{ESTRATÉGIA E TÁTICA NO VOLEIBOL}

Descritas as considerações sobre estratégia e táticas, considerando-se que o voleibol é uma modalidade esportiva de prática coletiva, pode-se concluir que a ele se aplicam as definições de estratégia e tática, coletiva e individual, trazidas acima para o desporto coletivo, senão vejamos: de acordo com Bizzochi (2013), o voleibol foi inventado em 1895, na cidade de Holyoke, no estado de Massachusetts, Estados Unidos, por William George Morgan, e é definida assim pelo mesmo autor:

O voleibol é um jogo praticado entre duas equipes de seis jogadores, dentro de uma quadra retangular dividida em dois quadrados iguais, separados por uma rede. O objetivo do jogo é fazer com que a bola passe por sobre a rede e caia na quadra adversária. Cada equipe pode tocar três vezes na bola e cada jogador não pode fazê-lo seguidamente. Os golpes na bola - geralmente desferidos com as mãos e com os antebraços - devem ser instantâneos, não sendo permitido retê-la. Os pontos são disputados a partir de uma ação denominada saque e consegue o ponto em disputa a equipe que alcançar o objetivo do jogo. As partidas são disputadas em sets de 25 pontos - exceto o quinto set, 
jogado em 15 pontos-, saindo-se vitoriosa a equipe que vencer três sets (BIZZOCHI, p. 2013, p.1).

Desta forma, o voleibol pode ser considerado uma modalidade esportiva coletiva, onde os oponentes se enfrentam alternando ações de ataque e de defesa.

O voleibol é jogado através de seis fundamentos técnicos, dos quais o saque, o levantamento e o ataque são os fundamentos classificados como ofensivos; e a recepção, o bloqueio e a defesa, fundamentos classificados como defensivos.

Em uma perspectiva de jogo, a equipe de voleibol deve ter uma estratégia geral para enfrentar seu oponente, a qual orienta a elaboração das estratégias específicas para cada fundamento ou, ainda, para cada grupo de fundamentos, os chamados sistemas ofensivo e defensivo. Após a elaboração das estratégias mencionadas, a geral e as específicas, parte-se então para a definição de quais táticas coletivas serão utilizadas para que se consiga cumprir as estratégias estabelecidas. Por sua vez, a tática individual será o fruto da percepção e decisão que o jogador terá no momento de agir.

Para colaborar com a afirmação anterior, mostrar-se-á como os conceitos estudados até aqui podem incidir sobre um fundamento do jogo, como por exemplo, no saque. $O$ saque é o fundamento que inicia a disputa do ponto no voleibol, ele é seguido por uma recepção do adversário, que quando bem executada, facilita o levantamento e o ataque da equipe que recebeu, logo, dificulta as ações defensivas da equipe que sacou. Portanto, é lógico pensar que sacar fortemente pode inibir a agressividade das ações de ataque do adversário.

Sendo assim, quando a estratégia geral de uma equipe é ser agressiva, frequentemente, durante o jogo, por considerar o adversário mais forte tecnicamente, a equipe em questão buscará evitar a troca de bolas, ou seja, busca finalizar as disputas de pontos o quanto antes. Essa estratégia incide sobre o saque também, que passa a ter a seguinte estratégia específica: sacar agressivamente para "quebrar" a recepção e fazer a bola voltar facilmente ou fazer o ponto direto sobre o adversário. Após isso, a tática, ou seja, a forma pela qual se buscará cumprir a estratégia, passa a ser definida através de suas variáveis, tais como: qual técnica, de onde, para onde, 
qual a distância e qual a altura deve-se sacar. A tática individual entra em ação na hora de executar o saque, onde o sacador deverá observar os jogadores da recepção adversária e, ao perceber algum tipo de antecipação, modificar, no último momento, uma das variáveis táticas anteriormente mencionadas e, caso não haja motivo para fazer tais modificações, deverá manter a programação tática coletiva.

Após o exposto, é possível compreender a importância tanto da estratégia, quanto das táticas coletiva e individual, bem como compreender a interação entre estes componentes, para se obter o sucesso em um jogo de voleibol.

\section{CONSIDERAÇÕES FINAIS}

Embora estratégia e tática pareçam iguais e busquem um mesmo objetivo, elas são diferentes. Essas diferenças nos esclarecem sobre a hierarquização que existe entre elas, bem como sobre a contribuição de cada uma no processo decisório, seja ele em âmbito militar, corporativo ou desportivo.

Fica claro, após a leitura do presente artigo, que falar-se em estratégia refere-se a pensamentos e ideias que norteiam ações precisas, ou seja, ações táticas, sobre algo que se pretende conquistar. Mais do que isso, clareia-se a organização entre os conceitos, onde percebe-se que para se cumprir uma estratégia estabelecida, é necessário a definição de, pelo menos, uma ação tática, e que esta pode se dar de várias formas.

Pode-se, portanto, conceituar estratégia como o plano de ação definido para se alcançar os objetivos almejados, enquanto que tática pode ser conceituada como a execução organizada dos procedimentos necessários para que se aplique uma estratégia definida.

No desporto, utilizando as definições propostas acima e as características da atividade esportiva, pode-se definir estratégia como o plano de ação definido para se superar o adversário tanto ofensiva quanto defensivamente. 
Já a tática pode ser definida como a execução organizada dos procedimentos necessários para se cumprir as estratégias ofensivas e defensivas. Por sua vez, a tática individual caracteriza-se por ser a solução encontrada e aplicada pelo jogador para ter sucesso frente a uma situação de oposição ao adversário.

O esclarecimento sobre o conceito de tática individual no desporto, vem permitir, a qualquer estrategista, uma reflexão sobre a importância da atuação individual do jogador dentro da tática de equipe.

A realização do presente artigo não tem qualquer pretensão de ser o ponto final sobre os conceitos analisados e propostos aqui, mas sim de ser um ponto de partida capaz de nos fazer refletir, ainda mais, sobre os mesmos. Ainda que estratégia e tática sejam termos que surgiram há muito tempo, na Grécia antiga, e que tenham sido muito utilizados em batalhas e guerras militares, seus conceitos são, atualmente, muito utilizados por organizações corporativas e também por equipes desportivas, fatos que mostram a importância de se compreender os referidos conceitos para se alcançar o sucesso profissional.

\section{REFERÊNCIAS}

AMORA, Antônio Soares. Minidicionário Soares Amora da Língua Portuguesa. 7. ed. São Paulo: Saraiva, 2000.

BIZZOCHI, Carlos. O voleibol de alto nível: da iniciação à competição. 4. ed. Barueri: Manole, 2013.

BOMPA, Tudor Olimpius. Treinando atletas de desporto coletivo. São Paulo: Phorte, 2005.

BORIM, Jayne Maria. Curso de jogos pré-desportivos. [201-]. Disponível em: <https://www.colaboraread.com.br/aluno/webaula/index/2118751601?atividadeDiscip linald=6235385\#3>. Acesso em: 10/06/2020. 
CARVALHO, Camila. Estratégia x Tática. Portal Administradores, publicado em: 29/07/2014. Disponível em: <https://administradores.com.br/artigos/estrategia-xtatica>. Acesso em: 05/06/2020.

CHIAVENATO, Idalberto. Introdução a Teoria Geral da Administração. 3. ed. Rio de Janeiro: Elsevier, 2004.

CONFEDERAÇÃO BRASILEIRA DE VOLEIBOL. Apostila do Curso Nacional de Treinadores de Vôlei de Praia - Nível II. Rio de Janeiro, 1998.

HERRERA, Wagner. Estratégia e Tática - 01. Portal do Marketing, publicado em: 24/05/2007.

Disponível

em:

$<\mathrm{http}: / /$ www.portaldomarketing.com.br/Artigos/Estrategia_e_Tatica_01.htm>. Acesso em: 02/06/2020.

HERRERA, Wagner. Estratégia e Tática. Blog Administração Estratégica, publicado em: 02/11/2006. Disponível em: <http://wagnerherrera.blogspot.com/2006/11/estratgia-e-ttica.html>. Acesso em: 01/06/2020.

LERBACH, Antônio Marcos et al. Apostila do Curso Especial de Voleibol. Blumenau: UniSesi, 2002.

SANTOS, Júlio Cesar De Souza. Estratégia: Origem, Conceitos e Definições. Portal Brasil Escola, publicado em: 04/03/2011. Disponível em: $<$ https://meuartigo.brasilescola.uol.com.br/administracao/estrategia-origemconceitos-definicoes.htm>. Acesso em: 01/06/2020.

TZU, Sun. A arte da guerra. Adaptação e Prefácio de James Clavell. 56. ed. Rio de Janeiro: Record, 2016.

TZU, Sun. A arte da guerra: os treze capítulos originais. São Paulo: Jardim dos Livros, 2011.

Enviado: Julho, 2020. 
Aprovado: Agosto, 2020. 